\title{
Construction machine scrubbing, water management
}

\author{
Luis Guillermo Dipotet Mollinedo* \\ Moscow State University of Civil Engineering, Yaroslavskoe shosse, 26, Moscow, 129337, Russia
}

\begin{abstract}
Faced with the pollution problem that they generate, the discharge of large volumes of wastewater, to the groundwater table, caused by cleaning operations in the machine scrubbing facilities and construction equipment in the network of workshops of the construction company in $\mathrm{La}$ Republic of Cuba.

The work for the solution of the proposed problem consists of the projection and execution of an installation, for the sedimentation of clay, dust, stones, heavy metals, as well as swimming fats, as a treatment, for the separation of solids, from the rest of the components of wastewater that result from the scrubbing process of construction equipment. The installation for the recovery of these important volumes of water; which is the essence of this article; its operation is based on the discrimination of waste, by its specific weights, resulting from scrubbing. For the processing of wastewater, a treatment system is conceived, with two multiple tanks placed in "cascades" where the settling of the solids is guaranteed, by undergoing two consecutive filtrations. At the end of the process, clean water is obtained, which will be reused for a new scrubbing, which accumulates in a clear water tank, thereby contributing to the saving of drinking water and energy, so necessary in human activity.
\end{abstract}

\section{Introduction}

Internationally, the importance of the protection and conservation of hydrographic basins is known, as a reservoir and supplier of a natural resource of great importance that is water [6]. Warnings issued at the end of the 20th century about the scarcity of fresh water have proven to be so accurate that today, lack of water threatens food security, livelihoods and human health (United Nations, 1992, and (IIPA), 2001) [5]. In addition, more than 3 billion people do not have access to safe water, and this problem is especially acute in developing countries.

Water and its use constitute, therefore, factors of strategic importance for the economy and the well-being of populations, and water management has become one of the greatest challenges of this 21 st century [6].

Water is the most common element on Earth and is a resource of inestimable value and essential for life on the planet.

In the Republic of Cuba, rainfall is the only source of water, which is not uniformly distributed in the country, due to the physical and geographical characteristics of the archipelago [10]. Since 2014, the Republic of Cuba has been hit by an intense drought, which has led to the evaluation of the water potential and the available resources of the hydrographic

\footnotetext{
${ }^{*}$ Corresponding author: mollinedo65@gmail.com
} 
basins, in order to achieve an integrated management of water and an efficient and productive use of water. appeal [9].

The scrubbing and greasing facilities in maintenance and repair facilities in Cuba are not sustainable, they do not have systems for separation and retention of mud, heavy metals, petroleum derivatives, etc., generated by the drag caused by the pressurized water that is applied on equipment for cleaning [14]. Nor is reuse foreseen; at the end of the process; of large volumes of water, which are dumped into the water table and sanitary systems [7].

The purpose of our work is precisely to positively influence this weakness presented by technical services to construction teams, and to totally reverse the process, not only avoiding contamination of the environment with the discharge of these hard waters, but also, reintegrating the water, already used, in a new useful scrubbing process [15].

\section{Methods}

In order to obtain the planned and expected results that solve the problem of contamination of the water table, as well as the optimization and savings in the cleaning operation in the cleaning facilities of machines and construction equipment in the construction company in the Republic of Cuba.

In the framework of research and experimentation, the following materials were prepared:

Because of the scientific materials developed, an analysis of Cuban standards was carried out on the subject of the study of construction machinery and equipment in tropical and humid conditions of the Republic of Cuba. The characteristics of scrubbing plants and solids, which are the waste generated in the scrubbing process, as part of the maintenance of construction machinery and equipment [15]. The indisputable advantage of using mathematical models to simulate the operating parameters of a hydraulic installation for settling solid waste and swimming fats was confirmed. We use MATHCAD, AUTOCAD, and others [3].

World experience has shown that advanced countries use these technologies effectively, such as the United States of America, France, China and England. They use simulation to operate their inventory of equipment and maintenance networks [2].

The "test tube method" [13] was used, manufacturing a small-scale settling facility, after the theoretical calculations and the simulation elements in the computer, confirming the calculations. We use two laboratories to analyze the water, before (contaminated residual water from scrubbing) and after, which is the water that resulted after the two decanting processes, already ready for reuse in new cleaning processes. The results were positive with a water ready for reuse.

\section{Results}

Location, natural and socioeconomic conditions of the environment where the Construction Company is located in the Republic of Cuba.

\section{Natural Conditions.}

The construction company is located in the north of the Republic of Cuba, in the Varadero Peninsula, very close to the Bay of Cárdenas located in the Caribbean Sea that is part of the Atlantic Ocean. The area where the company is currently located is characterized by being a coastal marine plain of cumulative origin of biogenic material, where a peat substrate originated on which a mangrove with a predominance of red mangrove and black mangrove developed, subjected to the constant effect of tides, marine spray and the accumulation of salts, as well as severe meteorological events such as severe local storms and hurricanes [15].

\section{Socioeconomic Conditions.}

The construction company of Varadero is located within a population settlement of 154,204 inhabitants. The company is a highly mechanized company, which has a park of machines and 
construction equipment of 2347 units. For the technical service of this numerous park, it has a network of fixed and mobile workshops, with their respective machinery and equipment scrubbing facilities that guarantee the operation of the machines and equipment as part of the complex, which includes the construction activities that it has. as objective the increasing increase of the yields in the construction, with the mechanization of the same, substituting the manual work [15].

As can be seen in the two graphs in Figures 1 and 2 shown below, the location of the company:

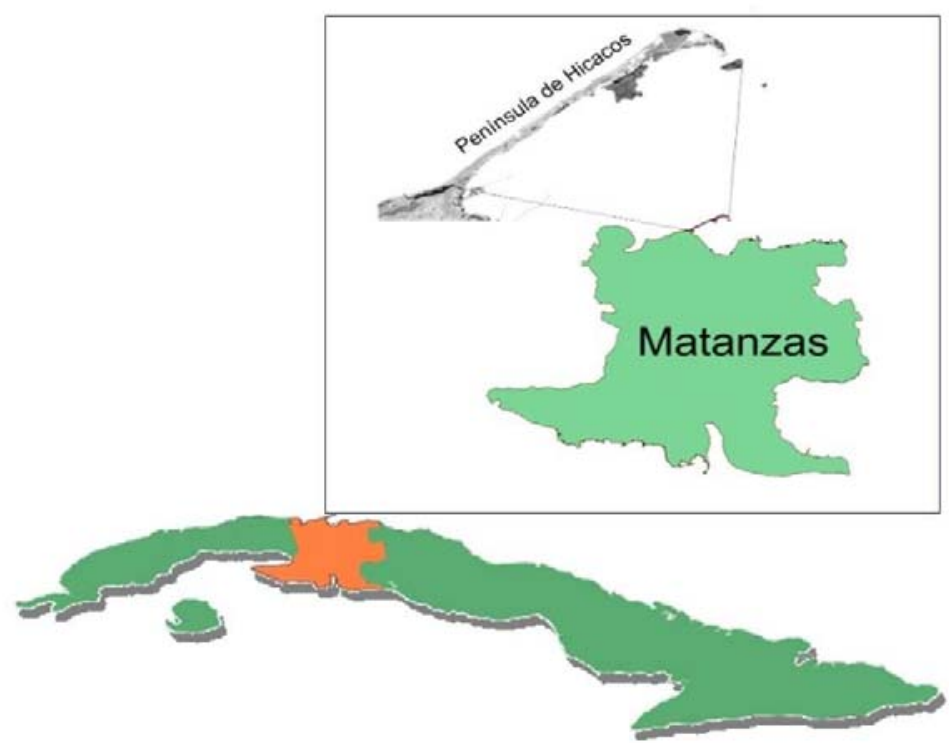

Fig. 1. Location of the construction company in the Republic of Cuba.

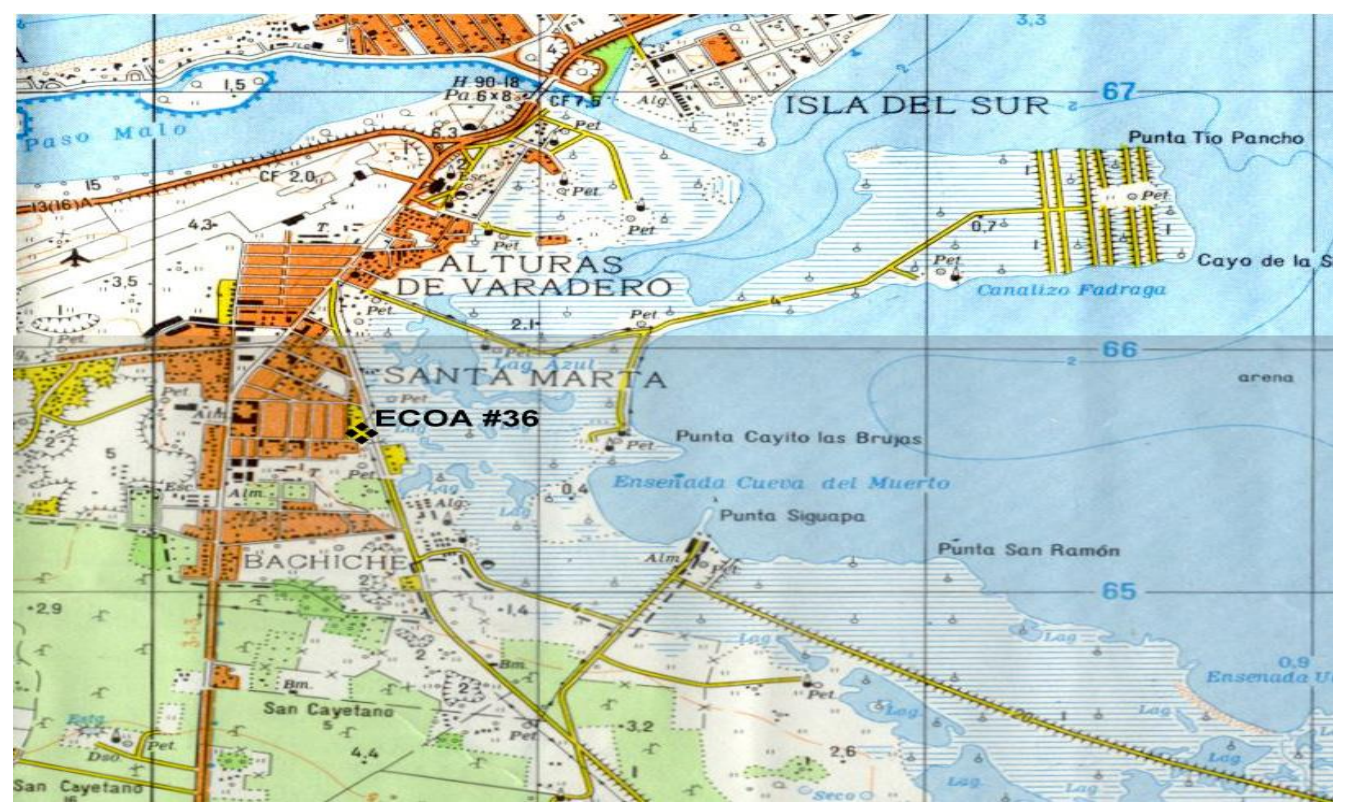

Fig. 2. Mapping of the area where the network of workshops is located in the Balearic of Varadero, Cuba. 
The mechanization of construction is the replacement of manual work in construction by machines and mechanisms. The main objective of construction mechanization is to increase labor productivity and free a person from heavy, laborious and tedious operations, and reduce the cost of construction [3].

The mechanization of construction is one of the main directions of technical progress; it ensures the development of the productive forces and serves as a material basis for increasing the efficiency of construction production, which is currently being intensively developed [1].

This work consists of the Design and Execution of a facility for the processing and recovery of residual water; resulting from the scrubbing process; in Scrubbing and Greasing Plants in workshops where Technical Services (Maintenance and Greasing) are performed. To achieve water purification and subsequent recovery and reuse we use the decantation method, based on the differences in specific weights of suspended solids (mud, stones, clay, metal particles, additives) and petroleum derivatives (swimming fats, oil lubricant, diesel).

For a standard Scrubbing Floor, we have an example for your calculation. The tank capable of achieving that the maximum hourly flow can be retained for at least one hour inside the tank and can decant $(60-70) \%$ of the settled solids contained in this residual.

To design the volume of this tank, the delivery capacity of the pump used for scrubbing is taken as the base or maximum hourly flow.

$\mathrm{Q}=15$ G.P.M equal a $3 \mathrm{~m}^{3} / \mathrm{h}$.

Assuming one-hour retention time, the tank volume is:

$\mathrm{V}=\mathrm{Q} * \mathrm{~T}=3 \mathrm{~m}^{3} / \mathrm{h} * 1 \mathrm{~h}(1)$

$\mathrm{V}=3 \mathrm{~m}^{3}$

With these parameters, the sludge-settling tank is designed, the dimensions of which appear in the Plan and Section plans.

These values are used to design the volume of the clear water tank where the pumping equipment is placed for use in the scrubbing activity.

This installation allows the recovery and use of a significant volume of water; already treated and recovered; avoiding its discharge to the environment and "soft, now achieving its recycling for its use.

Operacional Flow.

The water contaminated with oil derivatives and sludge from the scrubbing and greasing ramp enters the system through the first tank or sludge settler in which, due to its design dimensions, it is achieved that due to its specific weights and with the designed retention time $(60-70) \%$ of the solids are retained, this is allowed by the input and output devices, which result in communicating vessels located at different levels.

Subsequently, the water passes to the second fat separating tank that due to the difference in specific weights, the fat concentration rises and with its inlet and outlet devices it is possible to retain up to $90 \%$ of the supernatant fats, said effluent goes to the third separating tank of greases, in which with similarity of devices, a second separation of fats is achieved by passing this effluent to the fourth clear water tank that will serve as a supply source for the pump of the scrubbing equipment. 


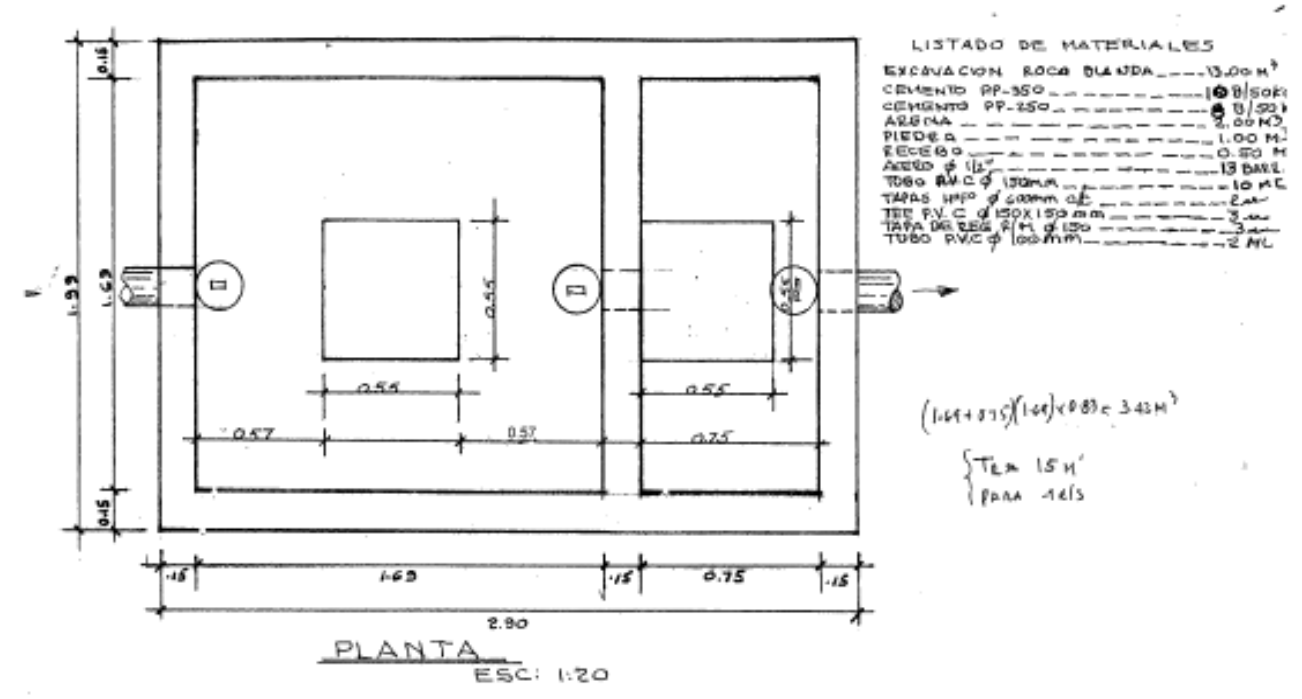

TRAMPA DE GRASA DEL TALLER

Fig. 3. Scheme, with the top view of the solids decanter plant.

$\underline{\text { Economic and environmental impact for companies with Scrubbing and Grease Plants. }}$

Taking as data the capacity of a standard electric pump that these plants have:

$\mathrm{Q}=3 \mathrm{~m}^{3} / \mathrm{h}$

and time $\mathrm{T}=5 \mathrm{~h} /$ day

Then the diary,

$\mathrm{Q}=$ es de $15 \mathrm{~m}^{3} /$ days

They are also spent annually,

$\mathrm{Q}=4700 \mathrm{~m}^{3} /$ annual

This volume is currently dumped into the medium and is not recycled or reused in most of the Scrubbing and Greasing Plants in Cuba, and most of those existing in the Ministry of Construction.

If we take into account the unit price of a cubic meter of water, which is $1.55 \mathrm{USD}$, it results in an annual expense of $\$ 7285.00$.

In the environmental part and taking into account the lack of water that is already appreciated and the global tendency to continue decreasing world reserves of this liquid elemental. We can consider:

- That a significant volume of water is saved, which is managed to recover and that was previously returned to the environment, making it necessary to use a new volume for the same activity. 
- It manages to soften these amounts of water through treatment, achieving not only its recovery but also that of the fats for recycling, which, if not carried out, would impact the water table, the flora and fauna of the entire area.

\section{Discussion}

The water purification and recycling system, a facility that operates in automatic mode, is designed to treat wastewater from manual washing of machines and construction equipment and high-pressure washers. The application of this system allows saving up to $75 \%$ of water due to its purification and reuse. The system, in addition to water purification, allows you to eliminate unpleasant odors caused by the presence of bacteria in the water.

An advantage of this method of treating wastewater in scrubbing facilities is that it does not use chemical substances for the purification of wastewater, which would also be a danger for the water table, flora, and fauna and for employees who they intervene in the scrubbing.

\section{Conclusions}

1. Decantation plants are designed and built for recycling large volumes of wastewater in the scrubbing facilities of the entire network of workshops of the construction company of the Republic of Cuba.

2. A decrease in the environmental impact is introduced that introduces the mechanization activity in the important tourist center of Varadero beach.

3. It is demonstrated that the rational use and exploitation of water resources is always possible.

4. Political will is necessary to undertake projects to save these resources and protect the environment.

Thanks to the Ministry of Construction of the Republic of Cuba, for the support and financing of the project. To the University of Havana for its support of its laboratories. To the Department of Construction Mechanization of the Moscow Civil Engineering University.

\section{Reference}

1. E.M. Kudryavtsev Comprehensive mechanization of the building. 3-ed. -M:, ASVB, 2010. $464 \mathrm{p}$.

2. E.M. Kudryavtsev Project 2003. Network planning and management of projects. TH.: DMK the Press. 2006. - 240 p.

3. E.M. Kudryavtsev Mathcad 11. The directory. -M:, DMK-press, 2006. - 184 p.

4. E. M. Kudryavtsev Mathcad 11. A full management under the Russian version.-M:, DMK press, 2005. - $592 \mathrm{p}$.

5. UN report on the state of the food insecurity in the world, 2001.

6. Introduction to Knowledge of the Environment. University for All Tabloid., 2002.

7. A. M., Borroto, Management ad economic energic. Cienfuegos, 2006. 104 p. 959-257-114-7

8. C.I.B.O Energy Efficiency Handbook. Virginy, 1997. 64 p.

9. C.M.E., Ed. Energy Efficiency: World Study. Indicators, Policies, Evaluation. Report of the World Energy Council in collaboration with, ADEME. London, 2004. 2500946121176

10. J. Campos Avella, Efficiency in Management Enterprise, 1998.

11. Enterprise energy management technology, CEEMA, 2000.

12. Business Energy Management. Hundred fires, Editorial Universo Sur, 2002. 104 p. 959257-040-X 
13. Work Guide for Key Positions Task and GTEE in the productive and services sector, 2006.

14. Efficient Total Energy Management Technology. Hundred fires,U. D. Cienfuegos, University of Cienfuegos "Carlos R. Rodríguez", 2005.

15. R. Espinosa Pedraja, Saving and rational use of energy. Part I. Chemistry- Pharmacy. Santa Clara, UCLV, 1991. 100 p.

16. N. N. Abramov. Theory and methodology for calculating supply and distribution systems water

17. Water supply // Great Soviet encyclopedia: in 30 volumes / ch.ed. A.M. Prokhorov. - 3rd ed. - M .: Soviet encyclopedia,1969-1978.

18. Water supply // Brief encyclopedia of household. -Moscow: State Scientific Publishing House "Great Soviet Encyclopedia", 1959.

19. SNiP 2.04.02. 84 Water supply. External networks and structures.

20. Reference books on the design and operation of water supply and sewerage systems. 